\title{
Diacetone alcohol decomposition and benzaldehyde Cannizzaro reaction as test reactions for the basic strength measurements of alumina, magnesia, Amberlyst type resins (A-15, XN 1010, A-26, A-21), Nafion NR 50 and solid sulfuric acid
}

\author{
Marek Marczewski ${ }^{1}$ D $\cdot$ Yuliya Kavalchuk ${ }^{1}$ - Urszula Ulkowska ${ }^{1}$ Marek Gliński ${ }^{1}$. \\ Osazuwa Osawaru²
}

Received: 15 May 2018 / Accepted: 1 November 2018 / Published online: 10 November 2018

(c) The Author(s) 2018

\begin{abstract}
The decomposition of diacetone alcohol to acetone proceeding at $303 \mathrm{~K}$ as well as the Cannizzaro transformation of benzaldehyde at $323 \mathrm{~K}$ leading to benzyl alcohol, can be regarded as useful test reactions in investigating the basic properties of solid catalysts. The minimum basic strength H_min needed to initiate the conversion of diacetone alcohol is within the range of 11.8-13.3, and for benzaldehyde transformation the value is 15.4. The above mentioned test reactions were used to study the basic strength of different solid acid-base catalysts. The conclusions can be presented as follows: (a) solid $\mathrm{NaOH}$ and Amberlyst type resin A-26 exhibit basic strength of $H_{-} \geq 15.4$ respectively, the basic centers of A-21 resin possess lower strength 11.8-13.3 $\leq \mathrm{H}_{-}<15.4$; (b) Amberlyst-15, Amberlyst XN 1010, Nafion NR 50 resins and solid sulfuric acid (SSA) possess basic strength of $\mathrm{H}_{-}<11.8-13.3$; (c) the basic strength of alumina and magnesia is $11.8-13.3 \leq \mathrm{H}_{-}<15.4$ whether they have been calcined at $753 \mathrm{~K}$ or not.
\end{abstract}

Keywords Basicity scale $\cdot$ Solid bases $\cdot$ Test reactions $\cdot$ Amberlyst resins $\cdot$ Nafion . Alumina $\cdot$ Magnesia $\cdot$ Solid sulfuric acid

Marek Marczewski

marekm@ch.pw.edu.pl

1 Chemistry Department, Warsaw University of Technology, Noakowskiego 3, 00-662 Warsaw, Poland

2 Industrial Chemistry Research Institute, Rydygiera 8, 01-793 Warsaw, Poland 


\section{Introduction}

The nature and activity of basic catalysts continues to be the basis of many reactions, which have found applications in industrial processes. These include, among others, the aldol condensations of: benzaldehyde with heptanal to jasmine aldehyde $(\mathrm{NaOH}$ or $\mathrm{KOH})$, n-butanal to 2-ethylhexenal $(30 \% \mathrm{NaOH})$, formaldehyde and acetaldehyde to acrolein $\left(\mathrm{NaOH}-\mathrm{SiO}_{2}\right)$; the Cannizzaro reaction of formaldehyde and pivaldehyde to pentaerythrol and formic acid $\left(\mathrm{NaOH}\right.$ and $\left.\mathrm{Ca}(\mathrm{OH})_{2}\right)$, the Guerbet condensation of: n-hexanol to 2-butyl-octanol $\left(\mathrm{MgO}-\mathrm{K}_{2} \mathrm{CO}_{3}-\mathrm{Cu}\right)$ or transalcoholysis of triglycerides to biodiesel ( $\mathrm{NaOH}, \mathrm{CH}_{3} \mathrm{ONa}, \mathrm{ZnAl}_{2} \mathrm{O}_{4}$, anionic resins) [1, 2].

The catalysts of these reactions activate the molecules of the substrate and transform to negatively charged particles, which undergo further reactions. In most cases substrate activation involves the detachment of the proton by the catalyst. Thus, the suitability of a basic catalyst is determined by its basic strength, i.e. the ability to remove a proton from an acid molecule- - a substrate of the reaction.

\section{The influence of the basic strength of the catalyst on a chemical reaction}

The catalyst not only activates the substrates allowing for the reaction to proceed but also influences the reaction rate. The latter phenomenon can be described in terms of the influence of the basic strength on the reaction rate. The basic strength of the solutions is quantitatively described according to Hammett [3] with the $\mathrm{H}_{-}$function defined by the formula (Eq. 1)

$$
\mathrm{H}_{-}=-\log \left(\mathrm{a}_{\mathrm{H}^{+}} \mathrm{f}_{\mathrm{A}^{-}} / \mathrm{f}_{\mathrm{HA}}\right)
$$

Here $\mathrm{a}_{\mathrm{H}^{+}}$is the proton activity and $\mathrm{f}_{\mathrm{A}^{-}}$and $\mathrm{f}_{\mathrm{HA}}$ are the coefficients of activity of the corresponding forms of the HA indicator:

$$
\mathrm{HA} \rightleftarrows \mathrm{H}^{+}+\mathrm{A}^{-}
$$

The basic strength of the solution can be determined directly (Eq. 3) by using an indicator of known $\mathrm{p} K_{\mathrm{A}}$ value and by measuring concentration of inert $\mathrm{HA}$ and ionized $\mathrm{A}^{-}$forms of the indicator:

$$
\mathrm{H}_{-}=\mathrm{p} K_{\mathrm{A}}-\log [\mathrm{HA}] /\left[\mathrm{A}^{-}\right]
$$

If a reaction catalyzed by a base proceeds according to the mechanism:

$$
\begin{gathered}
\mathrm{SH}+\mathrm{OH}^{-} \rightleftarrows \mathrm{S}^{-}+\mathrm{H}_{2} \mathrm{O} \\
\mathrm{S}^{-} \rightarrow \mathrm{P}
\end{gathered}
$$

Here $\mathrm{SH}$ and $\mathrm{P}$ are respectively the substrate and the reaction product and if it is of the first order, then according to Anbar et al. [4] the rate of reaction (r) depends on the basic strength of the catalyst as follows:

$$
\mathrm{r}=\mathrm{k}_{+} \mathrm{KK}_{\mathrm{W}} 10^{-\mathrm{H}_{-}}
$$


Here $\mathrm{K}, \mathrm{k}_{+}$and $\mathrm{K}_{\mathrm{W}}$ represent the equilibrium constant of the first step of the reaction (Eq. 4), the reaction rate constant of the second irreversible step (Eq. 5) and the equilibrium constant of the autoprotolysis of water.

The conversion of the reactant $\mathrm{S}$ into the product $\mathrm{P}(\mathrm{x})$ can be found directly by solving the above equation (Eq. 6). For a batch reactor, $\mathrm{x}$ can be expressed as:

$$
\mathrm{x}=1-\exp \left(-\mathrm{k} 10^{\mathrm{H}_{-}} \mathrm{t}\right)
$$

Here $\mathrm{k}$ and $\mathrm{t}$ are the reaction rate constant and reaction time.

Figure 1 illustrates the changes in the conversion of base catalyzed reaction as a function of basic strength $\mathrm{H}_{-}$of the catalyst, for the fixed values of $\mathrm{k}$ and $\mathrm{t}$. Depending on the susceptibility of the substrate to the attack of the base (k values), the position of the curves on an abscissa axis changes. This means that by selecting suitable substrates one can observe the appearance of their reaction products at different catalyst basic strengths.

Therefore, for low basic strength values, the substrate conversion is practically unchanged and remains close to zero. Only after exceeding a certain level of strength does it increase exponentially. It is therefore possible to determine the minimum basic strength (H_min) of the catalyst at which the substrate begins to react. Such a reaction plays the role of an indicator. The appearance of the transformation product $\mathrm{P}$ in the presence of the catalyst to be tested indicates that its basic strength $\mathrm{H}_{-}$is greater than or equal to the H_min of the substrate $\mathrm{SH}$ used in the test. Thus, substrates of varying proton donor ability, i.e. having different H_min values, can be used as probes for the test reactions. In order to perform such a measurement, it is necessary to: (1) identify suitable substrates that react under the influence of the bases, (2) determine the experimental values of H_min for them, (3) apply them in

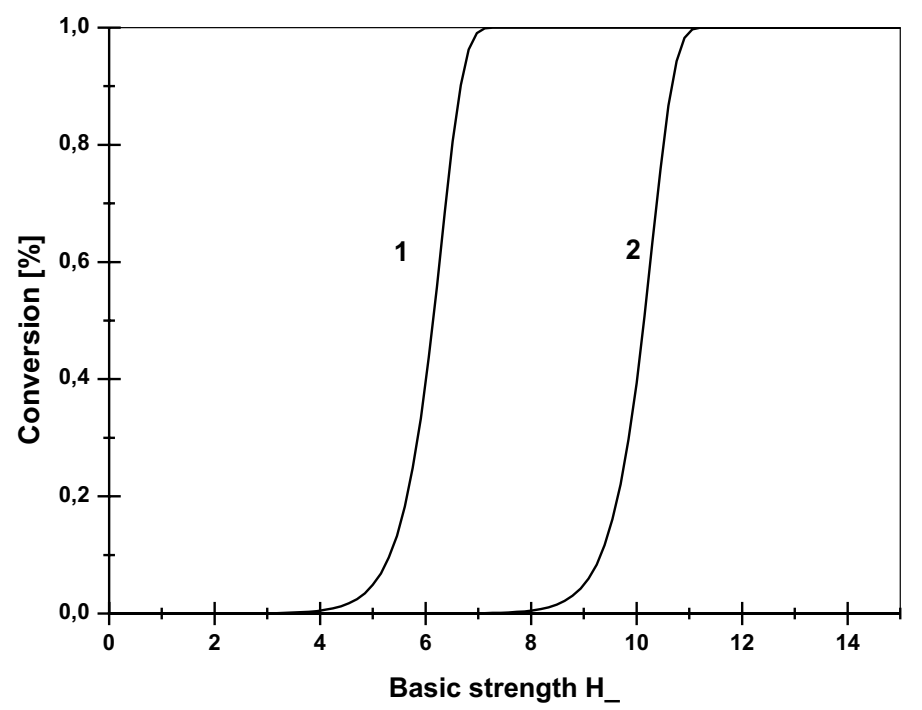

Fig. 1 Dependence of the calculated conversion (Eq. 7) of two test reaction substrates differing in susceptibility to base attack on the basic strength of the catalyst. Case 1: substrate with high proton donor ability. Case 2: substrate with low proton donor ability 
measuring the basicity of any specific catalyst. A similar approach has already been used successfully for acid strength measurements where, with various test reactions, we have determined the acid strength of a series of solid acids [5, 6].

\section{Selection of test reaction substrates}

The currently applied test reactions are used only to confirm the presence of basic centers and to classify them as of weak, medium or high strength. The examples of such reactions and reactants are:

- the Knoevenagel condensation of benzaldehyde with $\mathrm{XCH}_{2} \mathrm{Y}$ type molecules: ethyl cyanoacetate $(\mathrm{X}=\mathrm{CN}, \mathrm{Y}=\mathrm{COOEt})$, malononitrile $(\mathrm{X}=\mathrm{Y}=\mathrm{CN})$ and diethyl malonate $(\mathrm{X}=\mathrm{Y}=\mathrm{COEt})[7,8]$. The last three reactants differ in the $\mathrm{p} K_{\mathrm{A}}$ values of hydrogen in the methylene group, which are 9, 11 and 13 respectively. This makes it possible to compare the basic strength of various solid catalysts;

- the aldol condensation of butanal and isobutanal or acetone requires centers of basic strength equivalent to $13-14 \mathrm{pH}$ units $[9,10]$;

- transalcoholysis of ethyl acetate with methanol. The reaction requires the presence of basic centers of medium strength [8];

- the Michael condensation of cyclopentanecarboxylic acid, 2-oxo-, ethyl ester with methyl vinyl ketone [11]. In order to initiate this reaction, basic centers of higher strength basic centers than those catalyzing Knoevenagel condensation are required;

- the Cannizzaro reaction of benzaldehyde to benzyl alcohol and sodium benzoate. This reaction requires the presence of strong bases, e.g. 16.7 $\mathrm{M} \mathrm{NaOH} \mathrm{[12].}$

In the presented work, a reverse reaction to the acetone aldol condensation and the Cannizzaro reaction of benzaldehyde were chosen as test reactions. These reactions are well known and follow the equations presented below [13].

\section{Decomposition of 4-hydroxy-4-methylpentane-2-one (diacetone alcohol)}

The catalyst, in this case the $\mathrm{OH}^{-}$anion, removes $\mathrm{H}^{+}$from the hydroxyl group of the alcohol to form an aldol anion. The next step is the scission of the carbon-carbon bond in the aldol with the formation of acetone and the acetone carboanion. The reaction terminates the addition of the proton to the carboanion resulting in a second molecule of the reaction product-acetone formation (Scheme 1).

In the presence of acids, diacetone alcohol can be dehydrated to 4-methylpent3-en-2-one (mesityl oxide) (Scheme 2)

Dehydration can also take place in the presence of solid catalysts having Lewis acid type sites situated close to basic centers such as in the case of alumina [14, 15] (Scheme 3)

The results of diacetone alcohol transformation can be of use in the study of basic properties of catalysts, only if mesityl oxide is not present in the reaction products. Otherwise the results have to be considered with extreme care. 


\section{The Cannizzaro reaction of benzaldehyde}

The most frequently used catalyst for this reaction is an aqueous solution of $\mathrm{NaOH}$. The benzaldehyde particle attaches the hydroxide anion in the nucleophilic addition step. The formed anion transfers the hydride ion to the next aldehyde molecule to be transformed into benzoic acid. Moreover the benzaldehyde molecule is converted into a corresponding alcoholate ion. The reaction terminates with the transfer of the proton from the benzoic acid to the alcoholate ion resulting in a conversion product, i.e. benzyl alcohol. Thus, benzyl alcohol and sodium benzoate are formed by reacting the $\mathrm{NaOH}$ and two benzaldehyde molecules. Sodium benzoate can be regarded as a reaction product - benzoic acid irreversibly bound to the catalyst (Scheme 4).

The aim of the study was: (a) to investigate the suitability of the decomposition of diacetone alcohol and the Cannizzaro reaction of benzaldehyde as test reactions for the quantification of the basic strength of solid catalysts, (b) to determine the minimum basic strength necessary for initiation these reactions(H_min) and (c) to measure the basic strength of selected catalysts. The measurement of the minimum basic strength was performed using $\mathrm{NaOH}$ solutions of different concentrations and thus of different $\mathrm{H}_{-}$strength as catalysts. The solutions can be used individually, as a separate aqueous phase or as a solid. In the latter case, they are embedded in the structure of a porous solid carrier, to which they had earlier been introduced by dry impregnation. As active phase carriers, simple oxides such as, for example, $\mathrm{MgO}$, $\mathrm{Al}_{2} \mathrm{O}_{3}, \mathrm{SiO}_{2}$ or porous activated carbon were used. The choice of the proper support has to be verified experimentally as it can also affect the H_min value itself. For this reason, the samples of the carriers impregnated with only water were also examined as catalysts.

Test reactions should be carried out under strictly defined conditions such as temperature, amount of catalyst ( $\mathrm{NaOH}$ solution), amount of carrier, volume of substrate, type of reactor and reaction time. The same conditions must be adhered when measuring the basic strength of the catalysts tested. In order to validate the method, the reactions of diacetone alcohol and benzaldehyde were used to investigate the basic strength of various but well defined catalysts: (a) commercial Nafion and Amberlyst resins in which the different functional groups are immobilized in: perfluorinated polymer resin and styrene and divinylbenzene copolymers, (b) solid sulfuric acid (SSA) $\left(\mathrm{SiO}_{2}-\mathrm{ClSO}_{3} \mathrm{H}\right)$ [16], (c) systems of well known acid-basic properties such as $\mathrm{Al}_{2} \mathrm{O}_{3}[17,18], \mathrm{MgO}$ [17] and solid $\mathrm{NaOH}$. Amberlyst A-26 and Amberlyst A-21 are resins possessing only strongly basic $-\mathrm{CH}_{2}-\mathrm{N}\left(\mathrm{CH}_{3}\right)_{3}^{+} \mathrm{OH}^{-}$and weakly basic $-\mathrm{N}-\left(\mathrm{CH}_{3}\right)_{2}$ active groups [19, 20]. Nafion NR50, Amberlyst 15 and Amberlyst XN 1010 are typical solid acids having the same $\mathrm{SO}_{3} \mathrm{H}$ groups but bound to the perfluorinated polymer resin as well as to the polystyrene and divinylbenzene copolymers of different degree of crosslinking (Amberlyst XN 1010 resin is more strongly crosslinked than Amberlyst-15) [21], while $\mathrm{SO}_{3} \mathrm{H}$ groups in SSA are linked to an inorganic support $\left(\mathrm{SiO}_{2}\right)$. Magnesia and alumina are typical acid-base catalysts with strong and medium strength basic sites. The examination of such different solids with acid-base properties should allow the verification of the test reaction method and also the measurements of the basic strength of their active centers. 


\section{Experimental}

\section{Catalysts and carriers}

Amberlyst A-26, Amberlyst A-21, Amberlyst-15, Amberlyst XN 1010, Nafion NR 50 (Sigma-Aldrich) and three oxides: $\mathrm{SiO}_{2}$ (Karlsruhe ABCR, $\mathrm{S}_{\mathrm{BET}}=266 \mathrm{~m}^{2}$ $\mathrm{g}^{-1}$ ), $\gamma-\mathrm{Al}_{2} \mathrm{O}_{3}$ (Pierce Inorganics, $\mathrm{S}_{\mathrm{BET}}=98 \mathrm{~m}^{2} \mathrm{~g}^{-1}$ ), $\mathrm{MgO}$ (Ventron, $\mathrm{S}_{\mathrm{BET}}=$ $100 \mathrm{~m}^{2} \mathrm{~g}^{-1}$ ) and activated carbon (Norit) were used as the catalysts and carriers. Oxide supports and activated carbon with a grain diameter of $1.02-1.20 \mathrm{~mm}$ were used.

\section{Synthesis of solid sulfuric acid (SSA) [16]}

$10.0 \mathrm{~g}$ of $\mathrm{SiO}_{2}$ was initially dried at $423 \mathrm{~K}$ for $0.5 \mathrm{~h}$ under reduced pressure in a $100 \mathrm{~cm}^{3}$ two-neck flask equipped with a magnetic stirrer, a dropping funnel containing $3.0 \mathrm{~cm}^{3}$ of neat chlorosulfonic acid and a joint connection to link the system with a vacuum/dry $\mathrm{N}_{2}$ line. The flask was cooled after heating to ambient temperature and dichloromethane $\left(50 \mathrm{~cm}^{3}\right)$ was added in nitrogen atmosphere. Then a tube for evolving $\mathrm{HCl}$ leading to a trap filled with $\mathrm{Na}_{2} \mathrm{CO}_{3}$ water solution was connected. Subsequently, the content of the flask was stirred and chlorosulfonic acid was added dropwise over a period of $30 \mathrm{~min}$. Stirring of the content was continued for further 30-40 min till the end of $\mathrm{HCl}$ evolution. After removing dichloromethane (distillation) the obtained catalysts were stored in a desiccator.

\section{Determination of the minimum basic strength of test reactants}

The minimum basic strength necessary to initiate the reactions of diacetone alcohol and benzaldehyde in the presence of a catalytic system: $\mathrm{NaOH}$ solution/ substrate was determined as follows. $0.375 \mathrm{~cm}^{3} \mathrm{NaOH}$ solution of appropriate concentration was added to a glass vial $\left(5 \mathrm{~cm}^{3}\right)$ equipped with a screw closure and then $2 \mathrm{~cm}^{3}$ of the substrate (30 wt.\% of diacetone alcohol or benzaldehyde in toluene) was introduced. After closing the cap, the reactor was placed in the heating chamber (Mini Incubator 4010, GLF; shaking: $60 \mathrm{rpm}$, Shaker DOS-20S Elmi Ltd) at the appropriate temperature $(303 \mathrm{~K}, 313 \mathrm{~K}$ and $323 \mathrm{~K})$. After $20 \mathrm{~h}$, the organic phase was decanted and analyzed. In order to simplify the experimental procedure, measurements were also made in which the catalyst, i.e. $\mathrm{NaOH}$ solution, was placed by dry impregnation in pores of solid supports: $\mathrm{MgO}, \mathrm{Al}_{2} \mathrm{O}_{3}$, $\mathrm{SiO}_{2}$ as well as activated carbon. In this case, the step of the organic phase decantation could be omitted. So for systems support/aqueous $\mathrm{NaOH} /$ substrate the measurements were performed according following method. $0.500 \mathrm{~g}$ of a support (for $\mathrm{SiO}_{2} 0.125 \mathrm{~g}$ ) was placed in the reactor and then impregnated with an aqueous $\mathrm{NaOH}$ solution of appropriate concentration in the adequate amount for dry impregnation and $2 \mathrm{~cm}^{3}$ of the substrate was injected. After $20 \mathrm{~h}$, a sample was 
taken directly from the solution above the catalyst for analysis. The same experiments were also performed for pure water and pure water impregnated supports.

\section{Determination of the basic strength of solid catalysts}

Commercial resins such as Amberlyst A-26, Amberlyst A-21, Nafion NR 50, Amberlyst 15 and Amberlyst XN 1010 as well as SSA and solid $\mathrm{NaOH}$ were tested as for $\mathrm{NaOH}$ solution/substrate/support system $\left(0.500 \mathrm{~g}\right.$ of a resin $2 \mathrm{~cm}^{3}$ of the substrate) at $303 \mathrm{~K}$ (diacetone alcohol) and $323 \mathrm{~K}$ (benzaldehyde).

For magnesia and alumina catalysts, the experimental procedure was different. A sample of $0.500 \mathrm{~g}$ was placed in a glass batch reactor $\left(76 \mathrm{~cm}^{3}\right)$ connected to a vacuum/dry air metallic capillary tube line and calcined at $753 \mathrm{~K}$ for $4 \mathrm{~h}$ in a stream of dry air. The reactor was closed and cooled to ambient temperature. The catalyst was transferred, in the stream of dry air to the reactor and the substrate $\left(2 \mathrm{~cm}^{3}\right)$ added. The products were analyzed after $20 \mathrm{~h}$ of the reaction.

\section{Analysis}

The obtained reaction products were analyzed in a GC (Agilent $6890 \mathrm{~N}$ with FID detector) equipped with a $30 \mathrm{~m}$ HP5 capillary column (I.D. $0.32 \mathrm{~mm}, \mathrm{~d}_{\mathrm{f}} 0.25 \mu \mathrm{m}$, temperature $343 \mathrm{~K}(5 \mathrm{~min})$, to $543 \mathrm{~K}$ at $3 \mathrm{~K} / \mathrm{min}$ ).

Two methods were used to calculate substrate conversion. It was directly obtained from GC analysis and was evaluated on the basis of changes of substrate to toluene, an inert compound serving as an internal standard, ratio. In the latter case, the total conversion was calculated according to the following formula:

$$
x_{\text {total }}=1-\frac{\beta_{\text {substr. }}^{\tau}}{\beta_{\text {substr }}^{o} .}
$$

Here $x_{\text {total }}$ represents the total substrate conversion; $\beta_{\text {substr. }}^{o}=\frac{S_{\text {substr. }}^{o}}{S_{\text {stand. }}^{o}}, \beta_{\text {substr. }}^{\tau}=\frac{S_{\text {substr. }}^{\tau}}{S_{\text {stand. }}^{\tau} \text { are }}$ the ratios of GC peaks areas for substrate and internal standard (at beginning of the reaction and at reaction time equal to $\tau$ ).

\section{Results}

\section{Calibration of the test reaction method}

In order to apply the test reaction method for basic strength measurements, it is necessary to associate the reaction with the basic strength required to initiate it. The method used in determining the minimum basic strength needed to initiate a test reaction will be presented in the example of the decomposition of diacetone alcohol in the presence of aqueous solutions of $\mathrm{NaOH}$ as catalysts at $323 \mathrm{~K}$. The basic strength of the catalysts used has been taken from data already published [22]. The 


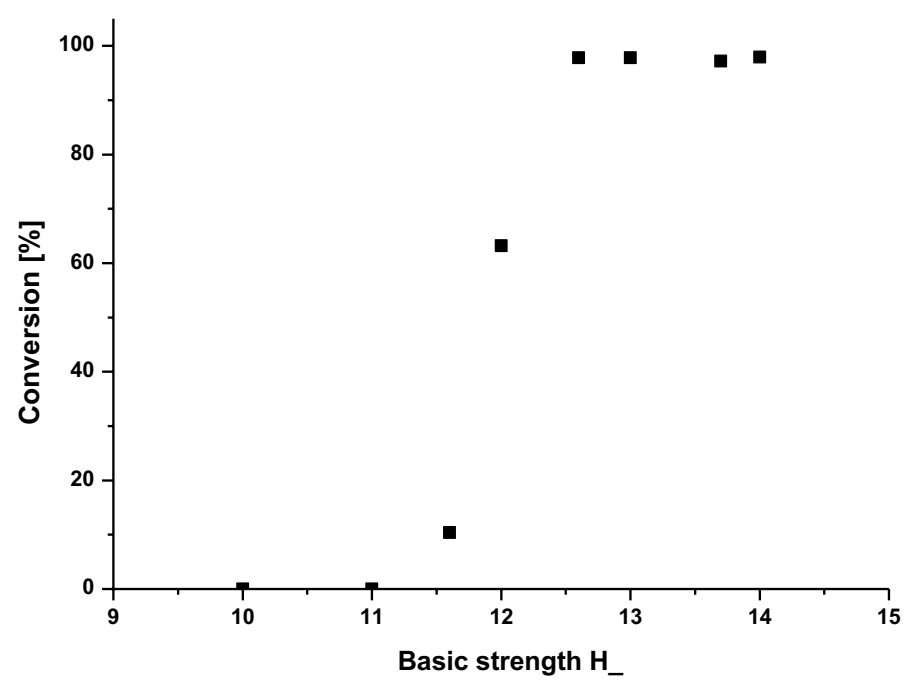

Fig. 2 Dependence of diacetone alcohol to acetone conversion $\left(\mathrm{x}_{\mathrm{GC}}\right)$ on the basic strength of the catalyst ( $\mathrm{NaOH}$ solutions) at $323 \mathrm{~K}$. Conditions: batch reactor, catalyst $0.375 \mathrm{~cm}^{3} \mathrm{NaOH}$ solution of appropriate concentration, substrate $2 \mathrm{~cm}^{3}$, reaction time $20 \mathrm{~h}$

obtained results are shown (Fig. 2) as diacetone alcohol to acetone conversion $\left(\mathrm{x}_{\mathrm{GC}}\right)$ vs. basic strength of the catalyst.

It can be seen that the obtained relationship is in good correlation with the expected nature of changes of the conversion (Fig. 1). The results, however, do not allow for the unambiguous indication of the value of a basic strength required to initiate the reaction. In order to determine this value, the first derivative of the curves describing the conversion of diacetone alcohol to acetone obtained from GC analysis $\left(\mathrm{x}_{\mathrm{GC}}\right)$ and based on an internal standard $\left(\mathrm{x}_{\beta}\right)$ were calculated, using Origin Pro software (OriginLab Corp.), and plotted (Fig. 3). The value of the basic strength was then marked at the level of half its height. It was arbitrarily accepted that these values represent of the minimum basic strength $H_{-}$min, which for this example amounts to 11.3 units for both $\mathrm{x}_{\mathrm{GC}}$ and $\mathrm{x}_{\beta}$. This value corresponds to diacetone alcohol conversion varying between $4 \%$ and $5 \%$ (values obtained from $\beta$ spline approximation of the experimental points).

Following the above procedure, all values of H_min were determined and summarized in Table 1.

In most cases, the H_min values for diacetone alcohol reaction decrease as the reaction temperature increases. This was observed for catalysts: $\mathrm{NaOH}-\mathrm{H}_{2} \mathrm{O}$, $\mathrm{NaOH}-\mathrm{H}_{2} \mathrm{O} / \mathrm{MgO}$ and $\mathrm{NaOH}-\mathrm{H}_{2} \mathrm{O} / \mathrm{SiO}_{2}$ systems. For two types of catalysts with $\mathrm{Al}_{2} \mathrm{O}_{3}$ and $\mathrm{C}_{\text {act }}$ as supports, such a relation was not observed. The H_min value was not influenced by temperature. Acetone was the only reaction product for catalysts: $\mathrm{NaOH}-\mathrm{H}_{2} \mathrm{O}, \mathrm{NaOH}-\mathrm{H}_{2} \mathrm{O} / \mathrm{MgO}$, as well as $\mathrm{SiO}_{2}$ and $\mathrm{Al}_{2} \mathrm{O}_{3}$ supported systems. A different behavior was observed when the catalyst system was $\mathrm{NaOH}$ solutions introduced into the pores of activated carbon- $\mathrm{NaOH}-\mathrm{H}_{2} \mathrm{O} / \mathrm{C}_{\text {act }}$. In this case of catalyst with low basic strength, mesityl oxide appeared in the reaction products indicating 


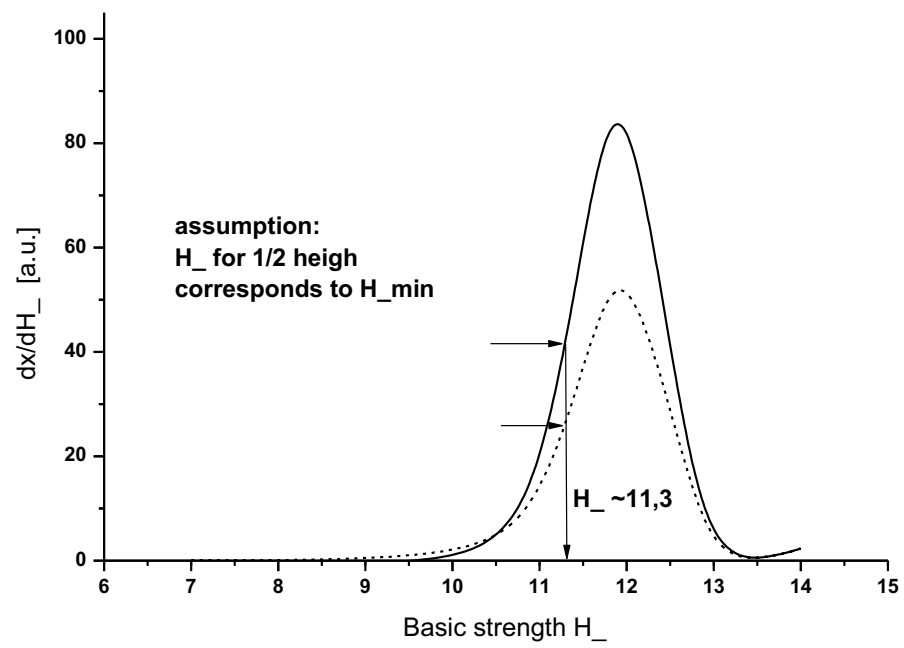

Fig. 3 Dependence of first derivative of diacetone alcohol to acetone conversion $\mathrm{x}_{\mathrm{GC}}$ (solid line) and $\mathrm{x}_{\beta}$ (dotted line) on the basic strength of the catalyst ( $\mathrm{NaOH}$ solutions) at $323 \mathrm{~K}$. Conditions: batch reactor, catalyst $-0.375 \mathrm{~cm}^{3} \mathrm{NaOH}$ solution of appropriate concentration, substrate $2 \mathrm{~cm}^{3}$, reaction time $20 \mathrm{~h}$

Table 1 The minimum basic strength required to initiate the conversion of diacetone alcohol to acetone and benzaldehyde to benzyl alcohol at different temperatures

\begin{tabular}{|c|c|c|c|c|c|}
\hline \multirow[t]{4}{*}{ Catalyst } & \multicolumn{5}{|c|}{$\begin{array}{l}\text { Minimum basic strength } \mathrm{H} \text { _min for the reac- } \\
\text { tion of }\end{array}$} \\
\hline & \multicolumn{3}{|c|}{ Diacetone alcohol } & \multicolumn{2}{|c|}{ Benzaldehyde } \\
\hline & \multicolumn{5}{|c|}{ Reaction temperature } \\
\hline & $303 \mathrm{~K}$ & $313 \mathrm{~K}$ & $323 \mathrm{~K}$ & $303 \mathrm{~K}$ & $323 \mathrm{~K}$ \\
\hline $\mathrm{NaOH}-\mathrm{H}_{2} \mathrm{O}$ & 11.5 & 11.4 & 11.3 & 15.4 & 15.4 \\
\hline $\mathrm{NaOH}-\mathrm{H}_{2} \mathrm{O} / \mathrm{MgO}$ & 12.7 & 12.3 & 11.8 & 15.4 & 15.4 \\
\hline $\mathrm{NaOH}-\mathrm{H}_{2} \mathrm{O} / \mathrm{Al}_{2} \mathrm{O}_{3}$ & 13.3 & 13.3 & 13.3 & & \\
\hline $\mathrm{NaOH}-\mathrm{H}_{2} \mathrm{O} / \mathrm{C}_{\mathrm{act}}$ & 13.6 & 13.6 & 13.6 & 15.4 & 15.4 \\
\hline $\mathrm{NaOH}-\mathrm{H}_{2} \mathrm{O} / \mathrm{SiO}_{2}$ & 13.7 & 13.4 & 13.1 & & \\
\hline
\end{tabular}

the presence of acid centers. Its content decreased as the basic strength of the catalyst increased. Acetone began to appear when mesityl oxide was not observed in the reaction products (Fig. 4).

This can be explained to be a result of sodium hydroxide reacting with carboxyl groups (acid sites) present on the surface of activated carbon able to catalyze mesityl oxide formation [23]. Acetone is obtained in the reaction catalyzed exclusively by the base $(\mathrm{NaOH})$ only after the neutralization of all acid sites.

The dependence of the H_min value and the conversion of diacetone alcohol to acetone on the nature of support was also observed. H_min values changed in the following sequence (Table 1, Fig. 5):

$$
\mathrm{NaOH}-\mathrm{H}_{2} \mathrm{O}<\mathrm{NaOH}-\mathrm{H}_{2} \mathrm{O} / \mathrm{MgO}<\mathrm{NaOH}-\mathrm{H}_{2} \mathrm{O} / \mathrm{Al}_{2} \mathrm{O}_{3}<\mathrm{NaOH}-\mathrm{H}_{2} \mathrm{O} / \mathrm{C}_{\text {act }}<\mathrm{NaOH}-\mathrm{H}_{2} \mathrm{O} / \mathrm{SiO}_{2}
$$




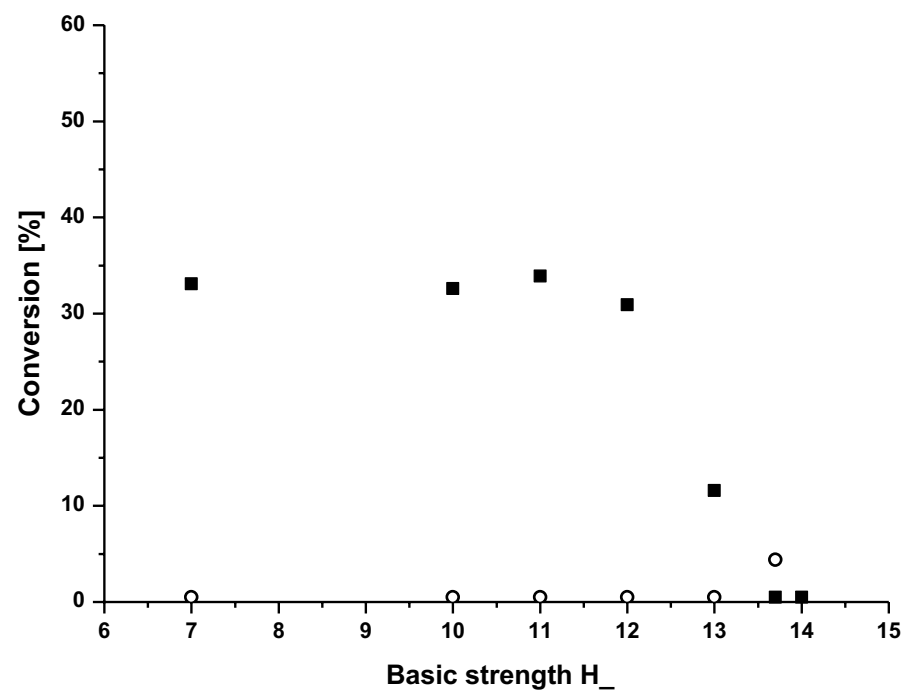

Fig. 4 Dependence of conversion of diacetone alcohol to mesityl oxide (filled square) and acetone (open circle) on basic strength of $\mathrm{NaOH}-\mathrm{H}_{2} \mathrm{O} / \mathrm{C}_{\text {act }}$ catalyst at $323 \mathrm{~K}$. Conditions: batch reactor, catalyst $0.5 \mathrm{~g}$, substrate $2 \mathrm{~cm}^{3}$, reaction time $20 \mathrm{~h}$

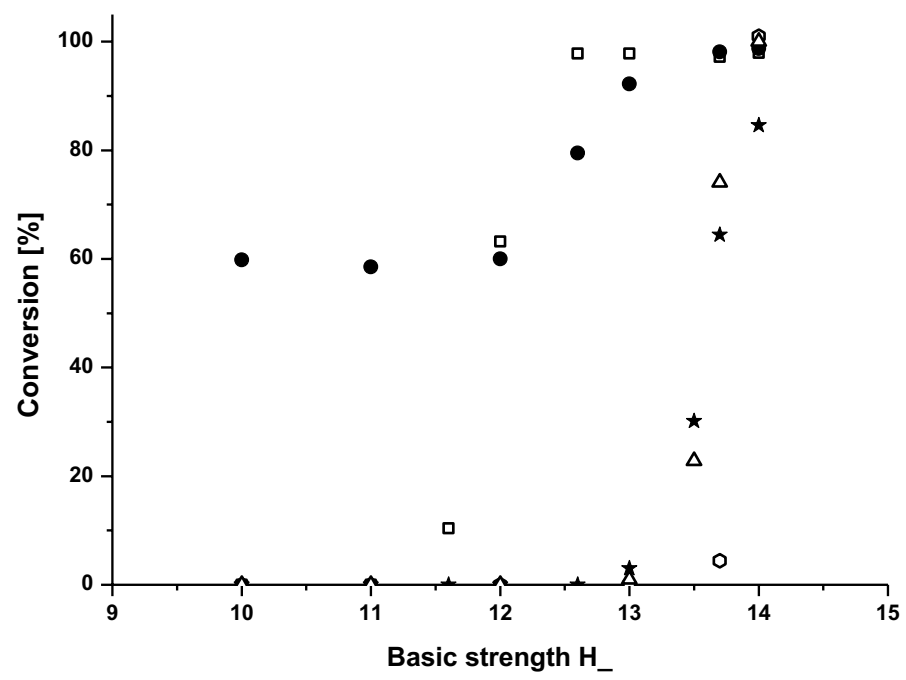

Fig. 5 Conversion of diacetone alcohol to acetone on basic strength of $\mathrm{NaOH}-\mathrm{H}_{2} \mathrm{O}$ (open square), $\mathrm{NaOH}-\mathrm{H}_{2} \mathrm{O} / \mathrm{MgO}$ (filled diamond), $\mathrm{NaOH}-\mathrm{H}_{2} \mathrm{O} / \mathrm{Al}_{2} \mathrm{O}_{3}$ (open triangle) and $\mathrm{NaOH}-\mathrm{H}_{2} \mathrm{O} / \mathrm{C}_{\text {act }}$ (open circle), $\mathrm{NaOH}-\mathrm{H}_{2} \mathrm{O}-\mathrm{SiO}_{2}$ (filled star) catalysts at $323 \mathrm{~K}$. Conditions: batch reactor, catalyst $0.5 \mathrm{~g}$, substrate $2 \mathrm{~cm}^{3}$, reaction time $20 \mathrm{~h}$

It can also be observed that even for low basic strength of $10<\mathrm{H}_{-}<11$, where the reaction does not occur in the presence of $\mathrm{NaOH}$ solution, the system 
$\mathrm{NaOH}-\mathrm{H}_{2} \mathrm{O} / \mathrm{MgO}$ catalyzes it efficiently (60\% conversion). This should indicate that $\mathrm{MgO}$ support apart of $\mathrm{NaOH}$ solution can catalyze the reaction.

The reactivity of pure carriers under calibration conditions are better illustrated in Table 2, where the results of diacetone alcohol reaction for the supports impregnated with pure water are presented.

Basic sites of $\mathrm{H}_{2} \mathrm{O} / \mathrm{MgO}$ catalyze diacetone alcohol decomposition at all reaction temperatures while acid centers of $\mathrm{C}_{\text {act }}$ transform diacetone alcohol into mesityl oxide (67\%) and acetone (33\%).

It is worth noting that the diacetone aldehyde decomposition is reversible. One can find the equilibrium conversion for the reverse reaction i.e. acetone aldol condensation. In the equilibrium state the amount of acetone converted varies from 9.1 to $4.3 \%$ for temperatures of 303 and $327 \mathrm{~K}$, respectively [24] Thus for diacetone alcohol decomposition, one can predict thermodynamic limits for conversion from 90.9 to $94.4 \%$. However, there are some reports that acetone can react with higher conversion than presented above equilibrium level [25]. Hence the equilibrium conversion values may not be precisely measured. The results presented in our work (Fig. 5) indicate that observed final diacetone alcohol conversion close to $97-99 \%$ are also slightly above the equilibrium level.

The second test reaction for which $\mathrm{H}_{-}$min measurements were performed was the Cannizzaro reaction of benzaldehyde. The reaction of benzaldehyde takes place at higher basic strength values H_min than the conversion of diacetone alcohol. Therefore, a higher concentration of $\mathrm{NaOH}$ solutions is required than in the case of diacetone alcohol reaction. Hence, $\mathrm{MgO}$ and $\mathrm{C}_{\mathrm{act}}$ both resistant on $\mathrm{NaOH}$ were selected as the carriers. In the case of the latter, the possibility of the reaction of surface carboxyl groups with $\mathrm{NaOH}$ should be taken into consideration. The reactions were carried out at two temperatures: 303 and $323 \mathrm{~K}$. No reaction was observed for values of low basic strength (Fig. 6). The reaction was initiated at a minimum basic strength H_min of approximately 15.4 units at both temperatures (Table 1).

The observed reaction product was benzyl alcohol. The second product i.e. sodium benzoate remained in the aqueous phase and was not analyzed. A similar transformation was observed when $\mathrm{NaOH}$ solution was used as the catalyst.

Table 2 Diacetone alcohol reactions catalyzed by water impregnated supports

\begin{tabular}{llllllr}
\hline Catalyst & \multicolumn{6}{l}{ Conversion to (\%) } \\
\cline { 2 - 7 } & \multicolumn{7}{l}{ Ac $c^{\mathrm{a}}$} & MO & A & MO & A & MO \\
& \multicolumn{7}{l}{ Reaction temperature } & & & \\
\cline { 2 - 7 } & $303 \mathrm{~K}$ & & $313 \mathrm{~K}$ & & $323 \mathrm{~K}$ & \\
\hline $\mathrm{H}_{2} \mathrm{O} / \mathrm{MgO}$ & 5.1 & 0.0 & 60.5 & 0.0 & 62.1 & 0.0 \\
$\mathrm{H}_{2} \mathrm{O} / \mathrm{Al}_{2} \mathrm{O}_{3}$ & 0.0 & 0.0 & 0.0 & 0.0 & 0.0 & 0.0 \\
$\mathrm{H}_{2} \mathrm{O} / \mathrm{SiO}_{2}$ & 0.0 & 0.0 & 0.0 & 0.0 & 0.0 & 0.0 \\
$\mathrm{H}_{2} \mathrm{O} / \mathrm{C}_{\text {act }}$ & 0.0 & 0.0 & 0.0 & 0.0 & 33.1 & 66.9 \\
\hline
\end{tabular}

${ }^{\mathrm{a}} \mathrm{Ac}$ and MO denote acetone and mesityl oxide respectively 


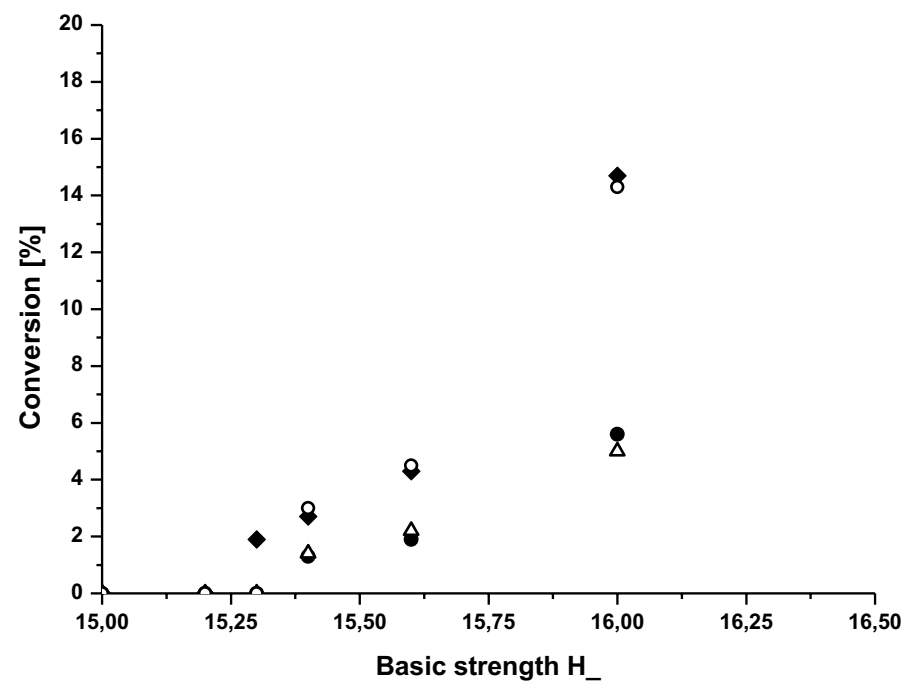

Fig. 6 Dependence of the degree of conversion of benzaldehyde on basic strength of the catalysts: $\mathrm{NaOH}-\mathrm{H}_{2} \mathrm{O} / \mathrm{MgO}$ at temperatures of $303 \mathrm{~K}$ (open circle) and $323 \mathrm{~K}$ (filled diamond) and $\mathrm{NaOH}-\mathrm{H}_{2} \mathrm{O} /$ $\mathrm{C}_{\mathrm{act}}$ at temperatures of $303 \mathrm{~K}$ (open triangle) and $323 \mathrm{~K}$ (filled circle). Conditions: batch reactor, catalyst $0.5 \mathrm{~g}$, substrate $2 \mathrm{~cm}^{3}$, reaction time $20 \mathrm{~h}$

\section{Basic strength measurements using test reaction}

The diacetone alcohol and benzaldehyde reactions were used to investigate basic strength of commercial resins: Amberlyst A-26, Amberlyst A-21, Amberlyst 15, Amberlyst XN 1010 and Nafion NR 50. The reactions were carried out at temperatures of $303 \mathrm{~K}$ for diacetone alcohol and $323 \mathrm{~K}$ for benzaldehyde (Table 3).

Amberlyst A-26 and A-21 resins catalyzed the reaction of diacetone alcohol to acetone with $100.0 \%$ selectivity. On the other hand Amberlyst 15, XN 1010 and Nafion NR 50 reacted in a different pathway to produce mesityl oxide with selectivities equal to $81.8,95.1$ and $92.9 \%$ respectively. Similarly, solid sulfuric acid (SSA) catalyzed the conversion of diacetone alcohol to mesityl oxide (selectivity $75.7 \%$ ). On the other hand, magnesium and aluminum oxides which were not subjected to calcination prior to measurements catalyzed the reaction only to acetone. After calcination in $753 \mathrm{~K}$, the appearance of mesityl oxide (selectivities: $\mathrm{Al}_{2} \mathrm{O}_{3}-15.9 \%$, $\mathrm{MgO}-2.2 \%$ ) was observed in the reaction products next to acetone. Benzaldehyde reacted only in the presence of A-26 resin and solid $\mathrm{NaOH}$.

\section{Discussion}

The knowledge of the acid or basic strength of a catalyst makes it possible to predict its potential for a number of chemical reactions. If their strength is too low, solid acid and bases would be unable to activate the substrate molecules by attaching or 
Table 3 Results of the test reactions of diacetone alcohol (303 K) and benzaldehyde (323 K). Conditions: batch reactor, catalyst $0.5 \mathrm{~g}$, substrate $2 \mathrm{~cm}^{3}$, reaction time $20 \mathrm{~h}$

\begin{tabular}{|c|c|c|c|c|}
\hline \multirow[t]{4}{*}{ Catalyst } & \multicolumn{3}{|c|}{ Test reaction of } & \multirow[t]{4}{*}{$\mathrm{MO} / \mathrm{Ac}$} \\
\hline & \multicolumn{2}{|c|}{ Diacetone alcohol } & \multirow[t]{2}{*}{ Benzaldehyde } & \\
\hline & \multicolumn{2}{|c|}{ Conversion/selectivity to (\%) } & & \\
\hline & $\mathrm{Ac}^{\mathrm{a}}$ & MO & BA & \\
\hline Amberlyst A-26 & $98.4 / 100.0$ & $0.0 / 0.0$ & 1.8 & 0.0 \\
\hline Amberlyst A-21 & $95.8 / 100.0$ & $0.0 / 0.0$ & 0.0 & 0.0 \\
\hline Amberlyst-15 & $18.5 / 18.9$ & $79.3 / 81.8$ & 0.0 & 4.3 \\
\hline Amberlyst XN 1010 & $3.3 / 4.1$ & $77.6 / 95.1$ & 0.0 & 23.5 \\
\hline Nafion NR50 & $5.3 / 7.1$ & $69.8 / 92.9$ & 0.0 & 13.2 \\
\hline SSA & $23.3 / 24.3$ & $72.7 / 75.7$ & 0.0 & 3.1 \\
\hline $\mathrm{Al}_{2} \mathrm{O}_{3}$ (not calcined) & $28.3 / 100.0$ & $0.0 / 0.0$ & 0.0 & 0.0 \\
\hline $\mathrm{Al}_{2} \mathrm{O}_{3}$ (calcined at $753 \mathrm{~K}$ ) & $82.7 / 84.1$ & $15.6 / 15.9$ & 0.0 & 0.2 \\
\hline $\mathrm{MgO}$ (not calcined) & $35.0 / 100.0$ & $0.0 / 0.0$ & 0.0 & 0.0 \\
\hline $\mathrm{MgO}$ (calcined at $753 \mathrm{~K}$ ) & $94.9 / 97.8$ & $2.1 / 2.2$ & 0.0 & $0.0^{\mathrm{b}}$ \\
\hline $\mathrm{NaOH}$ & $97.6 / 100.0$ & $0.0 / 0.0$ & 100.0 & 0.0 \\
\hline
\end{tabular}

${ }^{\mathrm{a}} \mathrm{Ac}, \mathrm{MO}$ and BA denote acetone, mesityl oxide and benzaldehyde

${ }^{\mathrm{b}}$ Exact value is 0.02

detaching the proton. Therefore, numerous methods have been developed over the years to describe and determine the acid or basic strength of solid catalysts. One of them is the use of Hammett Ho and $\mathrm{H}_{-}$scales [26, 27]. They allow for the comparison of the acid or basic strength of solids with the corresponding strengths of well known aqueous solutions of typical acids and bases such as $\mathrm{H}_{2} \mathrm{SO}_{4}$ or $\mathrm{NaOH}$. The classical measurement of the acid or base strength of solids involves the adsorption of a corresponding indicator and observing the color change, which occurs when the proton has been attached or removed [28]. If a change in color occurs, it is assumed that the acid strength $\left(\mathrm{H}_{\mathrm{O}}\right)$ is equal to or less than the value of $\mathrm{p} K_{\mathrm{BH}^{+}}$of the indicator and the base strength $\left(\mathrm{H}_{-}\right)$is greater or equal to the value of the indicator $\mathrm{p} K_{\mathrm{A}}$. This method has two major disadvantages. First, the measurement is correct if the socalled Hammett acids and bases are concerned. These systems are characterized by the fact that the only type of equilibrium i.e. the dissociation equilibrium of the protonated form of the indicator $\left(\mathrm{BH}^{+}\right)$or the neutral form of the indicator $(\mathrm{AH})$ takes place in the solution. Second, the color change of the indicator must be observable, which limits the measurements to white specimens. In our previous work, we developed another method of measuring acid strength, making use of the Ho scale by applying appropriate chemical reactions as indicators [29]. For such reactions, we have determined the minimum acid strength i.e. $\mathrm{H}_{\mathrm{O}}$ min needed for their initiation under strictly defined conditions (batch reactor, mass of catalyst, substrate volume, temperature and reaction time). To obtain catalysts of defined strength, aqueous solutions of sulfuric acid of various concentrations were introduced into the pores of an inert carrier $\left(\mathrm{SiO}_{2}\right)$. In this way, it was possible to determine the acid strength 
at which the reaction is initiated and substrates converted to products. The measurement of the acid strength of the solid acid (a catalyst) involving a series of test reactions under the calibration conditions of the method and determining which of them proceeded or not. This enabled the measurement of the acid strength of a series of various solid acids to be performed. In this work, we expected using a similar method for measuring the basic strength $\mathrm{H}_{-}$of the solid bases. Aqueous solutions of $\mathrm{NaOH}$ of specific basic strengths (concentrations) were used for the calibration method [22]. Working with a reaction system consisting of two liquids, an aqueous solution of catalyst and an organic phase containing the reagents, is quite problematic. After the reaction, one of the phase has to be separated by decantation so that organic phase can be analyzed. To simplify the procedure, we attempted to bind the aqueous phase of the catalyst with a solid carrier. In this case, the phase separation would not be necessary and the procedure would simply involve taking the reagent sample from the solution above the solid. On the other hand $\mathrm{NaOH}-\mathrm{H}_{2} \mathrm{O}$ /support catalytic system allows also to enhance the surface of liquid film of $\mathrm{NaOH}-\mathrm{H}_{2} \mathrm{O}$ catalytic phase due to dispersion on the surface of the carrier. Such catalyst is more close to real catalyst for which basicity measurements are performed than two liquid (aqueous phase-organic phase) system.

So the next step was to introduce $\mathrm{NaOH}$ solutions into the pores of the solid carrier using incipient wetness method. As the supports we selected: $\mathrm{MgO}$, which as the base solid should not interact with the base catalyst; $\mathrm{Al}_{2} \mathrm{O}_{3}$, which also exhibits some basic properties; $\mathrm{SiO}_{2}$, which can potentially react with $\mathrm{NaOH}$, but has often been used as a catalyst support for test reactions and activated carbon whose expanded pore network should facilitate the incorporation of the catalyst solution into the solid structure. As the test reactions, two transformations were chosen involving diacetone alcohol and benzaldehyde as reactants. The first is the reverse reaction to aldol condensation and the second one is the Cannizzaro<smiles>CC(=O)CC(C)(C)O</smiles><smiles>CC(=O)CC(C)(C)[O-]</smiles>

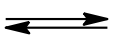<smiles>CC(C)=O</smiles><smiles>[CH2+]C(C)=O</smiles><smiles></smiles>

Scheme 1 Mechanism of base catalyzed decomposition of diacetone alcohol 
reaction. Both proceed in the presence of bases (Schemes 1 and 4), and, moreover, the diacetone alcohol may undergo other transformation i.e. dehydration to mesityl oxide if the catalyst is acidic instead of the basic one (Scheme 2). The obtained H_min values for the reaction of diacetone alcohol (Table 1) depend on both the reaction temperature and the method of introduction of the catalyst $\left(\mathrm{H}_{2} \mathrm{O}-\mathrm{NaOH}\right.$ solution) into the reacting system. The analysis of the results obtained for the reaction of diacetone alcohol with $\mathrm{MgO}$ as the catalyst solution support (Table 1, Fig. 5) leads to the conclusion that unmodified magnesium oxide can catalyze the formation of acetone. Therefore, the results obtained for the $\mathrm{NaOH}-\mathrm{H}_{2} \mathrm{O} / \mathrm{MgO}$ system should be disregarded. The results obtained for the $\mathrm{NaOH}-\mathrm{H}_{2} \mathrm{O} / \mathrm{C}_{\text {act }}$ catalyst (Table 1, Fig. 4) have to be disregarded also on the same basis. The support itself catalyzes the conversion of diacetone alcohol to mesityl oxide which confirms its acidic nature [23]. This results in the $\mathrm{NaOH}$ solution reaction in the pores with the acidic centers of the activated carbon, which change their concentration and then the basic strength. $\mathrm{SiO}_{2}$, in turn, is an oxide with weak acid properties and it is expected that surface-like analogues of sodium silicate could be formed. The acidic properties of silica were use for a method of $\mathrm{SiO}_{2}$ elimination from alumina rich fly ash for $\mathrm{Al}_{2} \mathrm{O}_{3}$ recovery. $\mathrm{NaOH}$ solution (15 wt.\%) at $368 \mathrm{~K}$ dissolved silica leaving alumina unreacted [30]. Thus, one can assume that sodium hydroxide solutions would not react at low temperatures with alumina support as it was in the case of silica. If the results obtained in the presence of $\mathrm{MgO}, \mathrm{SiO}_{2}$ and $\mathrm{C}_{\text {act }}$-containing catalysts are rejected, one $\mathrm{H} \_$min value from remaining should be chosen as a characteristic for the decomposition reaction of the diacetone alcohol. First, it is important to select the proper test reaction temperature. Due to the high volatility of the reaction product i.e. acetone it would seem that it is most advantageous to perform the test at the lowest possible temperature-303 K. At this temperature, the following H_min values were obtained: 11.5 for $\mathrm{NaOH}$ solution, and 13.3 for $\mathrm{NaOH}$ solution in $\mathrm{Al}_{2} \mathrm{O}_{3}$ pores. The minimum base strength values are close to each other, with a maximum difference of $1.8 \mathrm{pH}$ units. In such a case, it is reasonable to choose not a single value H_min but rather a range: $11.8-13.3 \mathrm{H}_{-}$units. The test conditions were established as follows: batch reactor, $0.5 \mathrm{~g}$ of a catalyst, $2 \mathrm{~cm}^{3}$ of a substrate,

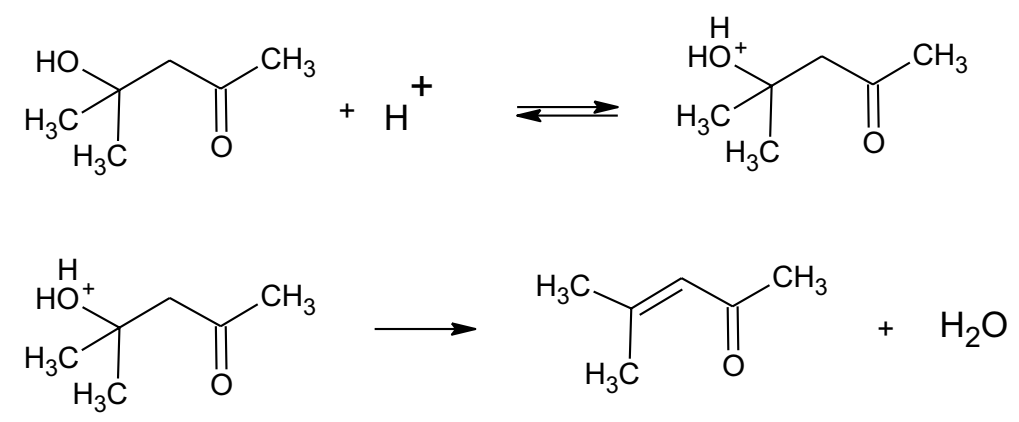

Scheme 2 Mechanism of acid catalyzed diacetone alcohol dehydration 
<smiles>CC(=O)CC(C)(C)O[18O]C[18O][18O]C(C)(C)CC(C)=O</smiles>

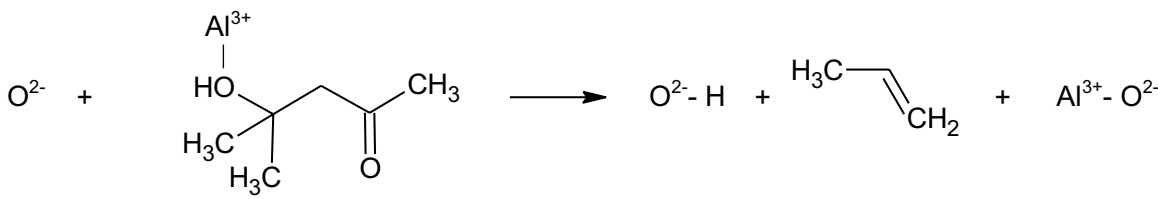

$$
2 \mathrm{Al}^{3+}-\mathrm{O}^{2-}+2 \mathrm{O}^{2-}-\mathrm{H} \longrightarrow \mathrm{Al}^{3+}+\mathrm{O}^{2-}+\mathrm{H}_{2} \mathrm{O}
$$

Scheme 3 Dehydration mechanism of diacetone alcohol in the presence of alumina [14]<smiles>CC(C)C([O-])O</smiles><smiles>[OH2+]C([OH2+])c1ccccc1</smiles><smiles>O=Cc1ccccc1</smiles><smiles>O=C(O)c1ccccc1</smiles><smiles>[O+]Cc1ccccc1</smiles><smiles>[OH2+]Cc1ccccc1</smiles><smiles>O=C(O)c1ccccc1</smiles>

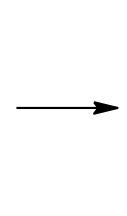<smiles>OCc1ccccc1</smiles><smiles>O=C([O-])c1ccccc1</smiles>

Scheme 4 Mechanism of benzaldehyde Cannizzaro reaction catalyzed by $\mathrm{B}^{+} \mathrm{OH}^{-}$base 
temperature $303 \mathrm{~K}$ and reaction time of $20 \mathrm{~h}$ and $\mathrm{H} \_$min value of diacetone alcohol reaction is between 11.8 and $13.3 \mathrm{H}$ _ units (Scheme 3 ).

The results obtained in the calibration of the method (Table 1) for the benzaldehyde reaction show that the H_min value 15.4 is not influenced by the reaction temperature $(303$ and $323 \mathrm{~K})$ or the catalyst form $\left(\mathrm{H}_{2} \mathrm{O}-\mathrm{NaOH}, \mathrm{NaOH}-\mathrm{H}_{2} \mathrm{O}\right.$ / $\mathrm{MgO}$ or $\mathrm{NaOH}-\mathrm{H}_{2} \mathrm{O} / \mathrm{C}_{\mathrm{act}}$ ). Thus the test conditions are: batch reactor, $0.5 \mathrm{~g}$ of a catalyst, $2 \mathrm{~cm}^{3}$ of a substrate, temperature $-323 \mathrm{~K}$ and reaction time of $20 \mathrm{~h}$ and H_min value of benzaldehyde reaction is $15.4 \mathrm{H}$ _ units. The choice of a higher reaction temperature- $323 \mathrm{~K}$ ensured a higher conversion of which enabled the interpretation of test results. In conclusion, the H_min values for diacetone alcohol and benzaldehyde test reactions were 11.8-13.3 and 15.4 Hammett scale units respectively. After establishing the H_min values the test reactions, they can be applied to measure the basic strength of the solid catalysts. Amberlyst A-26 and A-21 resins of basic character and Amberlyst-15, XN 1010 and Nafion NR 50 as well SSA with acid properties were selected for the measurements. For the latter resins, acid strength measurements were performed and Ho value was estimated to be: $-7.9<\mathrm{Ho} \leq-2.5$ for both Amberlysts and $-13<\mathrm{Ho} \leq-12$ for Nafion $[18,29,31,32]$. This choice of catalysts should be helpful in testing the reliability of the method used to measure the properties of both basic and acidic systems. The results obtained (Table 3) indicate that both A-26 and A-21 resins initiate the conversion of diacetone alcohol to acetone while the Cannizzaro benzaldehyde reaction proceeds only with $\mathrm{A}-26$ resin. So its base strength is $\mathrm{H}_{-} \geq 15.4$ while A-21 has a lower value of $11.8-13.3 \leq \mathrm{H}_{-}<15.4$. This confirms the higher basic strength of A-26 than A-21 [19, 20]. Only diacetone alcohol reacted in the presence of acidic resins and SSA catalyst leading mainly to mesityl oxide. It can be assumed that acetone, which also appears in reaction products, was formed by the action of acidic centers. Thus, the base strength of: Nafion NR50, Amberlysts 15 and $\mathrm{XN} 1010$ resins is low and is $\mathrm{H}_{-}<11.8-13.3$. The method validated with the results presented above can be used to study the surface properties of typical solid base as $\mathrm{MgO}$ and more complex catalyst systems possessing acid-base pair sites as in $\gamma-\mathrm{Al}_{2} \mathrm{O}_{3}$. Alumina and magnesia did not catalyze the transformation of benzaldehyde but initiated diacetone alcohol reaction to acetone (not calcined samples) and to acetone and mesityl oxide (calcined at $753 \mathrm{~K}$ samples). In the latter case the selectivities for $\mathrm{MgO}$ observed were 97.8 and 2.2\% while those for $\mathrm{Al}_{2} \mathrm{O}_{3}$ were 84.1 and $15.9 \%$ respectively. For a better interpretation of these results, the ratio of mesityl oxide to acetone was calculated (Table 3). For basic catalysts such as Amberlysts A-26 and A-21, solid $\mathrm{NaOH}$ and $\mathrm{MgO}$ it was found to be 0.0 , while it varied between 3 and 24 for acid catalysts such as Amberlysts 15 and XN 1010 and Nafion NR50 as well as SSA. These results indicate that basic sites in $\mathrm{MgO}$ in fact do catalyze the decomposition of diacetone alcohol and possess an acid strength of $11.8-13.3 \leq \mathrm{H}_{-}<15.4$. For alumina the results are not so unequivocal. The mesityl oxide to acetone ratio was 0.2 . This value is much less than the one observed for acid catalysts with Brønsted acid sites but evidently above zero. Hence, it can be postulated that basic sites of $11.8-13.3 \leq \mathrm{H}_{-}<15.4$ strength catalyze acetone formation while the same centers localized adjacent to Lewis acid sites are responsible for mesityl oxide formation (Schemes 1 and 3). 


\section{Conclusions}

Based on the results obtained, the following conclusions can be drawn:

- the decomposition of diacetone alcohol, to acetone, proceeding at $30{ }^{\circ} \mathrm{C}$, can be considered to be a test reaction in measuring the basic properties of the catalysts only in the absence of mesityl oxide in the reaction products or when the mesityl oxide to acetone ratio is close to zero;

- the minimum base strength H_min needed to initiate the conversion of diacetone alcohol is within the range 11.8-13.3. This value was derived from the examination of $\mathrm{NaOH}$ solutions itself and closed in alumina pores;

- the transformation of benzaldehyde (Cannizzaro reaction) leading to benzyl alcohol and benzoate anion bonded to a catalyst at $323 \mathrm{~K}$, may be considered a test reaction useful in investigating the basic properties of the catalyst;

- the minimum base strength H_min needed to initiate the conversion of benzaldehyde is 15.4 . This value was obtained from the system: $\mathrm{NaOH}$ solutions closed in magnesia and activated carbon pores;

- the base strength of the $\mathrm{A}-26$ resin and solid $\mathrm{NaOH}$ is $\mathrm{H}_{-} \geq 15.4$;

- the base strength of the A-21 resin is 11.8-13.3 $\leq \mathrm{H}_{-}<15.4$;

- the base strength of Amberlyst-15, Amberlyst XN 1010 and Nafion NR50 resins are $\mathrm{H}_{-}<11.8-13.3$ respectively;

- the base strength of SSA is $11.8-13.3<\mathrm{H}_{-}$;

- the base strength of calcined at $753 \mathrm{~K}$ and non calcined alumina and magnesia is $11.8-13.3 \leq \mathrm{H}_{-}<15.4$.

Acknowledgements This work was sponsored by Faculty of Chemistry, Warsaw University of Technology.

Open Access This article is distributed under the terms of the Creative Commons Attribution 4.0 International License (http://creativecommons.org/licenses/by/4.0/), which permits unrestricted use, distribution, and reproduction in any medium, provided you give appropriate credit to the original author(s) and the source, provide a link to the Creative Commons license, and indicate if changes were made.

\section{References}

1. Busca G (2008) Bases and basic materials in chemical and environmental processes. Liquid versus solid basicity. Chem Rev 110:2217-2249

2. Busca G (2009) Bases and basic materials in industrial and environmental chemistry: a review of commercial processes. Ind Eng Chem Res 48:5486-6511

3. Hammett P (1940) Physical organic chemistry. McGraw-Hill, New York

4. Anbar M, Bobtelsky M, Sammel D, Silver B, Jagil G (1963) The effect of ionic hydration on rate and equilibrium in concentrated alkaline solutions. II. The kinetics of base-catalyzed reactions in concentrated hydroxide solutions. J Am Chem Soc 85:2380-2384

5. Marczewski M, Kamińska E, Marczewska H (2013) Decomposition of styrene dimers: the influence of the acid strength of the catalyst. React Kinet Mech Catal 108:59-68

6. Marczewski M, Kamińska E, Marczewska H, Ciecierska K, Walczyk W (2014) Decomposition of styrene dimers on $\mathrm{Al}_{2} \mathrm{O}_{3}-\mathrm{Cr}$ and $\mathrm{Al}_{2} \mathrm{O}_{3}-\mathrm{SiO}_{2}-\mathrm{Cr}$ catalysts of acid and redox nature. React Kinet Mech Catal 111:549-567 
7. Climent MJ, Corma A, Fornes F, Frau A, Guil-Lopez R, Iborra S, Primo J (1996) Aluminophosphates oxynitrides as base catalysts: nature of the base sites and their catalytic implications. J Catal 163:392-398

8. Fujita SI, Bhanage BM, Aoki D, Ochiai Y, Iwasa N, Arai M (2006) Mesoporous smectites incorporated with alkali metal cations as solid base catalysts. Appl Catal A Gen 313:151-159

9. Kozlowski JT, Davis RJ (2013) Sodium modification of zirconia catalysts for ethanol coupling to 1-butanol. J Energ Chem 22:58-64

10. Lee S, Varma A (2015) Aldol condensation of n-butyraldehyde in a biphasic stirred tank reactor: experiments and models. AIChE J 61:2228-22239

11. Rodriguez I, Iborra S, Rey F, Corma A (2000) Heterogeneized Brönsted base catalysts for fine chemicals production: grafted quaternary organic ammonium hydroxides as catalyst for the production of chromenes and coumarins. Appl Catal A Gen 194-195:241-253

12. Hazlet SE, Stauffer DA (1962) Crossed Cannizzaro reactions. J Org Chem 27:2012-2024

13. March J (1968) Advanced organic chemistry: reactions, mechanisms and structure. McGraw-Hill Inc., New York

14. Abdel-Reihm MA, dos Santos ACB, Camorim VLL, da Costa Faro A (2006) Acid-base reactions on alumina-supported niobia. Appl Catal A Gen 305:211-218

15. Knozinger H, Sheglila A (1970) The dehydration of alcohols on alumina. XII. Kinetic isotope effects in the olefin formation from butanols. J Catal 17:252-263

16. Zolfigol MA, Khazei A, Mokhlesi M, Derakhsan-Panah F (2013) Synthesis, characterization and catalytic properties of monodispersed nano-sphere silica sulfuric acid. J Mol Catal A: Chem 370:111-116

17. Gates BC (1992) Catalytic chemistry. Wiley, New York

18. Marcilly C (2006) Acido-basic catalysis. Application to refining and petrochemistry. Editions Technip, Paris

19. Bellamy AJ (1994) Reaction of supported fluoride ion with gaseous sulphur mustard. React Polym 23:101-106

20. Trinadh M, Rajasekhar T, Bharu B, Gopinath J, Santosh V, Reedy BVS, Sainath AVS (2013) Solvent-free cyanoethylation of selected alcohols using Amberlyst A-21. Polym Resin J Appl Polym Sci 128:795-801

21. Park HS, Ihm SK (1985) Alkylation of benzene with 1-dodecene by macroreticular resin catalysis. Korean J Chem Eng 2:69-74

22. Yagil G, Anbar M (1963) The effect of ionic hydration on rate and equilibrium in concentrated alkaline solutions. I. The $H_{-}$function in aqueous alkaline solutions and the hydration of the $\mathrm{OH}^{-}$ion. J Am Chem Soc 85:2376-2380

23. Strelko W, Stavirskaya SS, Gorlov YuI (2014) Proton catalysis with active carbons and partially pyrolyzed carbonaceous materials. Chin J Catal 35:815-823

24. Podrebarac GG, Ng FTT, Rempel GL (1997) A kinetic study of the aldol condensation of acetone using an ion exchange resin catalyst. Chem Eng Sci 52:2991-3003

25. Sisul N, Cikovic N, Jelenic J (1991) Catalytic preparation of diacetone alcohol in controlled flow conditions. React Kinet Catal Lett 48:111-117

26. Paul MA, Long FA (1957) Ho and related indicator acidity functions. Chem Rev 57:1-44

27. Bowden K (1966) Acidity functions for strongly basic solutions. Chem Rev 66:119-131

28. Tanabe K (1970) Solid acids and bases. Their catalytic properties. Academic Press, New York

29. Marczewski M, Marczewska M, Popielarska D, Ciecierska D, Herman M, Kamińska A, Kamińska E, Wiedro R, Roguska A (2015) Styrene and styrene dimer derivatives, cyclohexene, tert-butylbenzene and cumene as test reactions for acid strength measurements of crystalline and amorphous silica-aluminas, sulfated oxides and Amberlyst. React Kinet Mech Catal 114:513-533

30. Liu XT, Wang BD, Yu GZ, Xiao YF, Wang XW, Shao LJ, Sun Q (2014) Kinetics study on predesilylation reaction for alumina recovery from alumina rich fly ash. Mater Res Innov 18(Suppl 2):S2-541-S2-546

31. Harmer MA, Sun Q (2001) Solid acid catalysis using ion-exchange resins. Appl Catal A Gen 221:45-62

32. Goncalves VLC, Rodrigues RC, Lorencato R, Mota CJA (2007) Assessing the acid strength of solid acid catalysts with the use of linear free energy relationship: H/D exchange with substituted benzene derivatives. J Catal 248:158-164 